\title{
EVIDENCES OF EFFICIENT INVESTMENT PORTFOLIO IN INDIAN CAPITAL MARKETS- AN ANALYSIS BASED ON BSE AND NSE INDICES
}

\author{
AUTHORED BY: \\ Dr. Deepshikha Mehta \\ Ph.D (Investment Structures), CFP. \\ Hamburg, Germany.
}

\begin{abstract}
:
A decent budgetary portfolio is nothing more, and nothing less, than an accumulation of advantages that develop in quality and produce abundance money for the financial specialist to spend or reinvest. Markowitz (1959) is one of the pioneers of present day portfolio hypothesis. Generally, the measure of danger utilized as a part of portfolio advancement models is the fluctuation. On the other hand, option measures of danger i.e., beta (un-standardized coefficient) has been utilized by Sharpe as a part of single file model. This paper goes for applying so as to build an ideal portfolio Sharpe's single record model. For this reason the day by day shutting costs of 50 organizations recorded on the National Stock Exchange (NSE) which include the Nifty Index would be considered for the period July 2012 to June 2014. The study shows financial specialist ought to be making interest in HCL Technologies Ltd. with an extent of 77.91\%, and Housing Development Finance Corporation Ltd. with an extent of 22.09\%. Financial specialist is obliged to short offer Bharat Petroleum Corporation Ltd., Asian Paints Ltd., United Spirits Ltd., and Bharti Airtel Ltd., stocks to expand portfolio return. This paper would be of extensive importance and valuable to the different financial specialists in determination of stocks for their portfolios.
\end{abstract}

Keywords: Indian capital market, Efficient Investment Portfolio, Stock markets, Investment, BSE, NSE

\section{INTRODUCTION:}

Portfolio is a blend of securities, for example, stocks, securities and currency business sector instruments. The procedure of mixing together the expansive resource classes in order to acquire ideal come back with least hazard is called portfolio development. Expansion of speculation serves to spread danger over numerous advantages. A Diversification of securities gives the certification of acquiring the foreseen return on the portfolio. In a broadened portfolio, a few securities may not execute not surprisingly, but rather others may surpass the desire and making the real return of the portfolio sensibly near the expected one. Keeping an arrangement of single security may prompt a more prominent probability of the genuine return fairly not quite the same as that of the normal return. Subsequently, it is basic practice to have a differentiated portfolio.

In unpredictable and complex markets, it is progressively difficult to plan an ideal speculation portfolio for association, customers, or for one's own self. In a developing business like India one is confronted with different speculation opportunities like stocks, obligation instruments, land, bullion, subordinates, and so forth., and as the 
different streets of venture expand molding, overseeing and checking of the portfolio turns out to be more mind boggling and entangled.

\section{LITERATURE REVIEW:}

Rodriguez, Michael Hardleand Wolfgang (2000) they analyze new approach for building record following portfolios with a confined number of stocks. They developed a two stages calculation that first gauges the connections between stocks and file in a versatile way and also figures the ideal weights that minimize the following slip. At long last the technique is connected to the DAX-Index and an examination with a gullible model that considers the genuine weights of every stock in the list is given. It gives the idea that the system succeeds in lessening the following lapse. Presentation of versatile relationship estimators doesn't enhance fundamentally the following blunder; by and by it acquires another dissemination of weights that is exploitable on the choice business so as to develop unpredictability arbitrages.

Sinha and Jayaraman (2012) point near investigation of routine beta modification strategies and recommend an enhanced Bayesian model for beta estimating. Further they recommended that for both single security and portfolio there was an inclination for moderately high and low beta coefficients to over foresee and under anticipate, individually, the relating betas for the ensuing time period.

Dr. Sathya Swaroop Debasish and Jakki Samir Khan (2012) did the examination on Optimal Portfolio Construction in Stock Market an Empirical Study on Selected Stocks in Manufacturing Sectors of India. Their examination target is to develop an ideal portfolio in Indian securities exchange with the assistance of the Sharpe single list model.In their study they chose 14 stocks from the different assembling areas like Automobiles, Cements, Paints, Textiles and Oil \& Refineries. They found that just three organizations stocks constitute the ideal portfolio and these were Asian Paints, Tata engines and Hero Motor Corp. with perfect extent of venture of $1.9 \%, 38.88$ and $58.22 \%$ individually. On the same line Mokta Rani Sarker (2013) did her study in Bangladesh and found that the ideal portfolio comprises of thirty three stocks chose out of 164 stocks which framed the DSE, giving the arrival of $6.17 \%$.

Niranjan Mandal(2013) in the examination of sharpe's single list model and its application to build ideal portfolio: an experimental studyfound that there was a noteworthy contrast between the aggregate danger of the ideal portfolio figured under two distinct instruments viz., Sharpe Index Modeland Markowitz's model. The aggregate danger of the ideal portfolio was $2.87 \%$ (as far as SD) under Sharpe Index Model and the aggregate danger of the portfolio was observed to be $1.79 \%$ (as far as SD) in Markowitz's model.

J. Ginger Meng, Gang Hu and JushanBai (2007) in their exploration "A Simple Method for Estimating Betas When Factors Are Measured with Error". They found that in relapses where macroeconomic variables are incorporated, utilizing OLIVE rather than OLS beta assessments enhances the R-squared fundamentally (e.g., from $31 \%$ to $80 \%$ ). Their outcomes in light of OLIVE beta evaluations help to determine two baffling discoveries by Lettau and Ludvigson(2001) and Jagannathan and Wang (1996): in the first place, the indication of the normal danger premium on the beta for the business sector return changes from negative to positive, steady with the hypothesis; second, the assessed estimation of normal zero-beta rate is no more too high (e.g., from 5.19\% to $1.91 \%$ for every quarter). 
JavedBin Kamal (2012) had done an exploration on ideal portfolio determination in ex stake stock value air pocket and moreover air pocket burst situation from Dhaka Stock Exchange with importance to Sharpe's single record model. He had done the examination with the target of applying so as to develop an ideal portfolio Sharpe's single record model of capital resource valuing in distinctive situations, one is ex stake stock value bubble situation and stock value air pocket and air pocket burst is second situation. It was found that all stocks neglected to make the pass Single Index Model criteria i.e. overabundance return over beta must be higher thanthe hazard free rate.

Impacts of Size and Allocation Method on Stock Portfolio Performance: A Simulation Study (2011) byKeat-Yung $\mathrm{Ng}$ and Kim-LengGoh, the outcomes demonstrate that the reenactment recommends an ideal portfolio estimate that ranges from 5 to 20 stocks and 11 stocks are the best for portfolio.

Yansen Ali (2008) inspected the single list model as one potential answer for streamline the estimation of ideal portfolios and look at its adequacy under distinctive settings of the model. He utilized three unique betas and thought about the portfolio and it was found that blume's system worked superior to the next two routines to gauge beta in single file model.

\section{DATA ANALYSIS TOOL:}

\section{Single Index Model:}

The Markowitz model is to a great degree requesting in its information requirements for producing the coveted proficient portfolio. It obliges $\mathrm{N}(\mathrm{N}+3) / 2$ evaluations ( $\mathrm{N}$ expected returns $+\mathrm{N}$ differences of profits $+\mathrm{N} *(\mathrm{~N}-1) / 2$ remarkable covariance of profits). In view of this restriction the single record model with less info information prerequisites has risen. The Single file model obliges $3 \mathrm{~N}+2$ assessments (evaluations of alpha for every stock, appraisals of beta for every stock, appraisals of change for every stock, gauge for expected profit for business file and an evaluation of the fluctuation of profits available record) to utilize the Markowitz advancement system.

\section{Construct the portfolio:}

i. Calculate the excess beta ratio

Excess return to beta ratio $=(\mathrm{Ri}-\mathrm{Rf}) / \mathrm{b}$

ii. Rank the stock from highest to lowest excess return to beta ratio

iii. The next step is to determine the stocks for which the excess return to beta ratio is higher than a particular unique cutoff point $\mathrm{C}^{*}$.

$$
\mathrm{C} i=\frac{\sigma_{\mathrm{m}}{ }^{2} \Sigma\left(\mathrm{R}_{\mathrm{i}}-\mathrm{R}_{\mathrm{f}}\right) \beta_{\mathrm{i}}}{1+\sigma_{\mathrm{m}}{ }^{2} \Sigma \beta_{\mathrm{i}}{ }^{2} / \sigma_{\mathrm{ei}}{ }^{2}}
$$

Where:

$\sigma \mathrm{m}^{2}=$ variance in the market index 
$\sigma_{\mathrm{ei}}{ }^{2}=$ variance of a stock's movement that is not associated with themovement of the market index: this is the stock's unsystematic risk

iv. The next step is to calculate the percentage to be invested in each security which is given by:

$$
\begin{aligned}
\mathrm{X}_{\mathrm{i}}^{0}=\mathrm{Z}_{\mathrm{i}} / \Sigma \mathrm{Z}_{\mathrm{i}} \text { where } \\
\mathrm{Z}_{\mathrm{i}}=\frac{\beta_{\mathrm{i}}}{\sigma_{\mathrm{ei}}{ }^{2}} \frac{\left.\mathrm{R}_{\mathrm{i}}-\mathrm{R}_{\mathrm{f}}-\mathrm{C}^{*}\right)}{\beta_{\mathrm{i}}}
\end{aligned}
$$

\section{OBJECTIVES:}

The study has been directed for to develop portfolio and the study has been led on individual securities recorded in National Stock Exchange of India (NSE). The destinations of this study are:
A. Risk - return investigation of individual securities recorded in NSE.
B. Construct ideal portfolio utilizing Single record Model.
C. Assist financial specialists in portfolio determination procedure to settle on the right decision.

\section{METHODOLOGY:}

This is an unmistakable study on building an ideal value portfolio. The information taken for the study is auxiliary in nature. The information has been gathered from the official site of National Stock Exchange (NSE), in particular www.nse-india.com. The study is directed in light of the money related information for as long as two years from July 2012 to July 2014. The example size of the study is constrained to every day stock shutting cost of 50 organizations which are recorded on NSE and are a piece of CNX NIFTY.The study is in light of the Sharpe Index Model and henceforth the constraints of the model may innate in the study.

\section{DATA ANALYSIS AND RESULT:}

\begin{tabular}{|l|l|l|l|l|}
\hline Company Name & $\mathbf{R i}-\mathbf{R f} / \mathbf{B i}$ & $\mathbf{\Sigma}(\mathbf{R i}-\mathbf{R f}) \mathbf{B i} / \mathbf{\sigma}^{\mathbf{2}}{ } \mathbf{i}$ & $\mathbf{\Sigma}_{\mathbf{i}}{ }^{2} / \mathbf{\sigma}^{\mathbf{2}}{ }_{\mathbf{i}}$ & $\mathbf{C i}$ \\
\hline HCL Technologies Ltd. & $\mathbf{7 . 2 5 2 8 2 3}$ & 0.001743 & 0.000240 & 0.001705 \\
\hline Housing Development Finance Corporation Ltd. & $\mathbf{1 . 6 4 5 0 6 3}$ & 0.002386 & 0.000631 & 0.002333 \\
\hline Bharat Petroleum Corporation Ltd. & $\mathbf{1 . 6 3 2 7 3 5}$ & 0.002641 & 0.000787 & 0.002582 \\
\hline Asian Paints Ltd. & $\mathbf{1 . 4 1 2 4 5 7}$ & 0.003634 & 0.001490 & 0.003550 \\
\hline Wipro Ltd. & $\mathbf{1 . 1 4 6 3 1 4}$ & 0.624547 & 0.543150 & 0.399011 \\
\hline United Spirits Ltd. & $\mathbf{0 . 8 6 9 9 6 3}$ & 0.976430 & 0.947631 & 0.495721 \\
\hline BhartiAirtel Ltd. & $\mathbf{0 . 6 4 8 7 6 2}$ & 0.976481 & 0.947709 & $\mathbf{0 . 4 9 5 7 2 7}$ \\
\hline Jindal Steel \& Power Ltd. & 0.464301 & 0.980338 & 0.956018 & 0.495595 \\
\hline
\end{tabular}


The choice of the stocks relies on upon a novel cut-off rate such that all stocks with higher proportions of overabundance come back to beta are incorporated and stocks with lower proportion are forgotten. The total estimations of $\mathrm{Ci}$ begins declining after a specific $\mathrm{Ci}$ and that point is taken as the cut-off point and that stock proportion is the Cut-off proportion $\mathrm{C}$. The most elevated estimation of $\mathrm{Ci}$ is taken as the cut-off point that is $\mathrm{C}^{*}$. From above table it is seen that Bharti Airtel Ltd. has the most noteworthy the cut-off rate of $C^{*}=0.495727$. Every one of the stocks having $\mathrm{Ci}$ above than $\mathrm{C}^{*}$ can be incorporated in the portfolio. With this paradigm, 7 stocks to be specific HCL Technologies Ltd., Housing Development Finance Corporation Ltd., Bharat Petroleum Corporation Ltd., Asian Paints Ltd., Ltd., United Spirits Ltd. Also, Bharti Airtel Ltd. qualifies to be incorporated in the ideal portfolio.

\begin{tabular}{|c|c|c|c|}
\hline Company Name & $\mathbf{C i}$ & $\mathbf{Z i}$ & $\mathbf{X i}$ \\
\hline HCL Technologies Ltd. & 0.001705 & 0.065212 & 0.779099 \\
\hline Housing Development Finance Corporation Ltd. & 0.002333 & 0.01849 & 0.220901 \\
\hline Bharat Petroleum Corporation Ltd. & 0.002582 & -0.00521 & \\
\hline Asian Paints Ltd. & 0.003550 & -0.00357 & \\
\hline Wipro Ltd. & 0.399011 & -0.37977 & \\
\hline United Spirits Ltd. & 0.495721 & -0.09774 & \\
\hline BhartiAirtel Ltd. & 0.495727 & -0.00064 & \\
\hline
\end{tabular}

By utilizing Sharpe file model, we have the capacity to figure out the extent of ventures to be made for each of the two stocks included in the ideal portfolio. The most extreme venture ought to be made in HCL Technologies Ltd. with an extent of $77.91 \%$, and Housing Development Finance Corporation Ltd. with an extent of $22.09 \%$. Investors are needed to short offer Bharat Petroleum Corporation Ltd., Asian Paints Ltd., United Spirits Ltd. what's more, Bharti Airtel Ltd. Stocks to build portfolio return.

\section{REFERENCES:}

Ali Y(2008) Simplifying the Portfolio Optimization Process via Single Index Model. Accessed from http://www.iems.northwestern.edu/docs/undergraduate/honors/Ali.pdf

Dema, T. (2015). The Real Trade-Off between Opportunity Cost and Uncertain Profit. Journal: Scholedge International Journal of Management \& Development, 2, 24-28.

Dr. Sathya Swaroop Debasish and Jakki Samir Khan (2012) Optimal Portfolio Construction in Stock Market- An Empirical Study on Selected Stocks in Manufacturing Sectors of India,Opinion: International Journal of Business Management, ISSN: 2277-4637, Opinion Vol. 2, No. 2, pp 37-44. 
El El Namaki, M. S. S. (2015). Strategies For Offense And Defense In Global Capital Markets. Scholedge International Journal of Management \& Development ISSN 2394-3378, 2(5), 68-74.

Gajera, M. A., Vyas, M. P., \& Patoliya, M. P. (2015). Risk and Return Analysis Of BSE Small, Medium \& Large Capitalization Indices. Scholedge International Journal of Management \& Development ISSN 2394-3378, 2(4), 3237.

J. Ginger Meng, H.Gand B J(2007) A Simple Method for Estimating Betas When Factors Are Measured with Error. Accessed from

http://www.columbia.edu/ jb3064/papers/2011_A simple method_for_estimating betas when factors are measur ed_with_error.pdf

Javed bin kamal (2012) optimal portfolio selection in ex ante stock price bubble and furthermore bubble burst scenario from dhaka stock exchange with relevance to Sharpe's Single Index Model, Financial Assets and Investing, no.3, pp. 29-42.

Keat-Yung Ng and Kim-LengGoh (2011) Effects of Size and Allocation Method on Stock Portfolio Performance: A Simulation Study, 3rd International Conference on Information and Financial Engineering IPEDR vol.12 (2011) () (2011) IACSIT Press, Singapore.

Mokta Rani Sarker(2013) Optimal Portfolio Construction: Evidence from Dhaka Stock Exchange in Bangladesh, World Journal of Social Sciences, Vol. 3. No. 6. Pp. $75-87$.

NiranjanMandal (2013) sharpe's single index model and its application to construct optimal portfolio: an empirical study, Great Lakes Herald Vol.7, No.1, March 2013, pp 1-21.

P.Sinha and P.Jayaraman, Empirical analysis of the forecast error impact of classical and bayesian beta adjustment techniques, MPRA, Paper No. 37662, March 2012.

Rodriguez, Michael and Härdle Wolfgang (2000).Modeling DAX-Tracking Portfolios with adaptive BetaEstimators.Accessed on December 2013 from http://edoc.hu-berlin.de/master/rodriquez-michael-2000-0928/PDF/rodriquez.pdf.pp. 1-31.

Surendar, G. (2015). Equity Investment Strategies: A Study On Retail Investors In India. Scholedge International Journal Of Management \& Development Issn 2394-3378, 2(6), 19-32. 